\title{
Ethical Navigation in Leadership Training
}

\author{
Oyvind Kvalnes ${ }^{1} \&$ Einar Overenget ${ }^{2}$ \\ ${ }^{1}$ BI Norwegian Business School, oyvind.kvalnes@bi.no; ${ }^{2}$ Academy of Humanities, \\ einar@humanistisk-akademi.com
}

Business leaders frequently face dilemmas, circumstances where whatever course of action they choose, something of important value will be offended. How can an organisation prepare its decision makers for such situations? This article presents a pedagogical approach to dilemma training for business leaders and managers. It has evolved through ten years of experience with human resource development, where ethics has been an integral part of programs designed to help individuals to become excellent in their professional roles. The core element in our approach is The Navigation Wheel, a figure used to keep track of relevant decision factors. Feedback from participants indicates that dilemma training has helped them to recognise the ethical dimension of leadership. They respond that the tools and concepts are highly relevant in relation to the challenges that occur in the working environment they return to after leadership training.

Keywords: business ethics, leadership training, dilemma

\section{Introduction}

The purpose of this article is to present a pedagogical approach to dilemma training for business managers and leaders. In the past ten years we have been responsible for ethical training sessions in programs designed to help individuals develop their leadership skills. We have used elements from moral philosophy in attempts to cultivate the participants' theoretical understanding of the morally challenging situations they can encounter in their practice as managers and leaders. This experience has given us the opportunity to bring philosophical theories and concepts in contact with everyday challenges in business. The practical aim has been to strengthen the participants' abilities to handle dilemmas in their professional activities and to voice their own moral viewpoints and considerations.

The activity can be seen as a concrete way of countering what Bird and Waters have called the moral muteness of business managers (Bird and Waters 1989; Bird 1996). They claim that people are morally mute if they fail to forthrightly voice moral concern regarding issues about which they possess moral convictions. Bird and Walters have interviewed a high number of people within the business community and conclude that many of them hold moral convictions yet fail to verbalise them. Their work highlights the need to 
provide training for people within business to articulate their moral concerns and engage in ethical reflection.

Over the past decades, dilemma training of various forms has been recognised as a useful element in preparing individuals and organisations for moral challenges. A wide range of methodological approaches are available (see e.g. van Luijk 1994; Laczniak \& Murphy 1985; Rion 1990; Nash 1989; Blanchard \& Peale 1988). The common assumption in all approaches is that people can prepare for morally challenging situations by learning to meet them in a systematic manner, equipped with a set of questions and principles to guide them in the ex ante analysis leading up to a decision and in the ex post justification of what they have decided to do. Our own method is one of many possible ways of conducting dilemma training. We have chosen to frame it in terms of ethical navigation: How can a responsible individual in business navigate well in an area of moral challenges and concerns?

The first part of the article addresses the concept of a dilemma and how it can be distinguished from other difficult decision situations. The conceptualisation builds on a number of contributions to the understanding of the nature of dilemmas (Toffler 1986; Maclagan 2003; Jackson 1996; Brinkmann 2005). In one form or another they all distinguish between (1) dilemmas as situations where a person faces conflicting moral duties, and (2) situations where it may be clear what the morally right course of action is, but where it is tempting to do something else. Maclagan operates with a continuum between dilemmas, defined as situations where 'whichever action is taken it will offend an important moral value', and 'quasi-moral dilemmas' (Maclagan 2003: 23), which may be more of a test of will than of moral reasoning. A similar understanding forms the basis for our own approach.

The main component of our dilemma training approach is the Navigation Wheel. We present it in the second part of the article. It is a figure highlighting six aspects that should be taken into account when considering the alternatives open to the decision maker: legality, identity, morality, reputation, economy and ethics. The Navigation Wheel is closely related to methods presented in other dilemma approaches, most notably in works by van Luijk (1994), Marinoff (2002), Mclagan (2003), Blanchard and Peal (1988), Rion (1990), Laczniak and Murphy (1985), Nash (1989) and the Markkula-center (2007). The Navigation Wheel has evolved as a pedagogical tool partly as a response to these approaches and partly through experience in conducting dilemma training. It is not the purpose here to argue for the supremacy of the Navigation Wheel approach as a framework for case analysis, in comparison to the alternative methods mentioned previously. Instead, this article is our way of sharing the conceptual ideas and the experiences we have had with the Navigation Wheel as the core element in ethical training and learning processes.

\section{Real and false dilemmas}

What is a moral dilemma? Our understanding of the concept is similar to that of Jackson, who defines a dilemma as a situation 'where whatever you do seems to be wrong' (1996: 
35). A moral dilemma, then, can be seen as a choice between wrong and wrong. The decision maker faces a situation where two moral values or duties make demands on him, but he can only honour one of them and thus will violate one important moral concern, no matter what he decides to do. The same line of thinking is expressed by Maclagan, who states that ' $(d)$ ilemmas arise when, faced with a difficult situation (e.g. fair treatment for some versus job security for others), two or more such values conflict in the perception of a decision maker, or when one is assessing another's moral choice' (Maclagan 2003:22). A person facing a dilemma must decide which moral duty to prioritise, and 'whichever action is taken it will offend an important moral value' (Maclagan 2003: 23). In defining a dilemma as a situation where one faces conflicting moral duties, Maclagan follows a conceptualisation presented by Toffler (1986).

Moral dilemmas are the starting point of our dilemma training sessions. The decision maker has to give priority to one moral value over another. In a wider sense, dilemmas can occur within the framework of values in a wider sense. A business leader needs to take into account not only the moral aspects of his alternatives but also legality, identity, reputation, economy, as well as aspects highlighted by ethical concepts, principles and theories. The tension between such decision factors creates dilemmas in a wider sense.

Dilemmas can require analysis and reflection, both in order to decide ex ante what to do and in order to justify the choice ex post. However, not all situations people tend to call dilemmas deserve that label. Maclean draws a distinction between quasi-moral dilemmas and acute moral dilemmas. The former can be situations where matters of self-interest or selfishness make the agent inclined towards one of the options available to him. $\mathrm{He}$ has a moral duty to do A, but his personal interests would be better served by him doing B. In this case the choice is between right and wrong, rather than wrong and wrong. In business ethics, the distinction between these types of situations has also been labelled as one between dilemmas and temptations (Kidder 1995: 7; Brinkmann 2005: 183). In our own teaching, we have asked the participants to be aware of the difference between real dilemmas and false dilemmas, along the lines suggested in the contributions from Maclean, Kidder and Brinkmann.

Some of the cases we use in ethical training can be difficult to categorise as either acute/real or quasi/false dilemmas. Like Maclagan we find it useful to assume that there is a continuum from the truly acute dilemmas to the quasi dilemmas. Some difficult choices may not be dilemmas at all. It can nevertheless be valuable to bring them up in ethical training and for common reflection, not in order to make an effort to identify the right choice (that might be obvious) but to acknowledge the challenges embedded in temptations and false dilemmas.

It is our experience that common efforts to place a particular dilemma on the continuum between real and false can create a fruitful dialogue. One reason for this is the extent to which the pursuit of self-interest on a personal as well as on an organisational level can be allotted some moral value. Protection of one's own economic security has a moral dimension to it (Maitland 2002: 5), and not standing up to defend one's own interests can be seen as a form of servility (Hill 1985). 
Dilemmas are at the core of our ethical training sessions. Here is an example of a case we use as input for ethical reflection:

Ben is the manager of a small private banking unit within a large financial services group. Results have slumped recently, mainly due to a bitter conflict between one employee and some of his colleagues. They complain that he is rude and difficult to cooperate with. Ben has made several attempts to mitigate, to no avail. Key members of Ben's unit have become very upset by the situation and have started to look for work elsewhere. Now, the employee himself has applied for a job in a different part of the financial services group. Ben has agreed to serve as a reference person. He receives a phone call from the manager of the unit currently contemplating to hire the employee. She is particularly interested in the employee's social skills. 'Does he function well with his colleagues?' she asks. If Ben gives an honest answer, he is likely to be stuck with the employee for a long time. If he is more vague with regard the truth, he may get rid of a problem, but runs the risk that his honesty will come up for questioning later.

Ben's dilemma is a classic, generic dilemma. Where exactly does it belong on the continuum between real and false dilemmas? That will depend on the further details of the case. Many participants convey their experiences from being on both sides of the table under circumstances where one party is strongly tempted to keep silent about the negative features of a person applying for a job. Some have been untruthful as reference persons. Among those, some have lived to regret it because the choice has backfired. When the employee ends up in the same kind of conflicts at the new workplace, questions are asked about the honesty of the reference person. Others convey that they came away with one less burden on their shoulders. No further questions were asked about how and why they withheld information. We have also encountered managers who have been open and honest about the employee's problems and have been forced to find other means to deal with the conflict. American leaders have failed to grasp the tension of Ben's situation. 'What is the problem?' they say. 'Why doesn't Ben just fire the man with cooperation difficulties?' Our work has taken place in cultures where the legal scope for firing people in this manner is very limited.

The responses people have to Ben's dilemma expose their moral outlooks or what Forsyth (1980) has called their personal moral philosophies. When we ask for justification of the choice of either being truthful or not, the participants at our courses have come up with a wide variety of reasons, expressing their individual loyalties and preferences. The first response is often that one alternative or another feels right or wrong. Two people disagreeing on what should be done will compare feelings and conclude that they feel differently about the case. Our task has been to illustrate the steps you can take in order to become clearer about the moral issues at stake and to progress from a state of mismatching feelings to one where the participants are able to recognise the ethical and moral foundations for their own choices. 


\section{Ethical Navigation}

The core element in the conceptual toolbox we apply in dilemma training is The Navigation Wheel. It presents six main areas of inquiry when considering the options available to a decision maker.

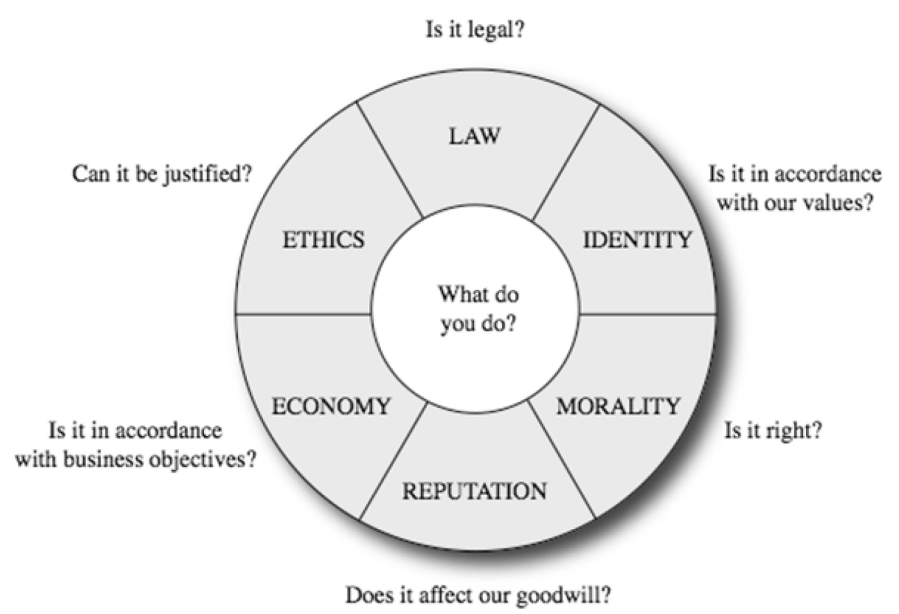

Figure 1

One noticeable distinction we make in the Navigation Wheel is that between ethics and morality. In everyday speech, these concepts are sometimes used synonymously. We thus normally start a dilemma training session by explaining the distinction and why we make it. Adopting the definitions made by Goodpaster ${ }^{1}$ and by Blanchard and Rosenthal ${ }^{2}$ we understand morality as a set of personal and shared beliefs about right and wrong, developed over time, while we see ethics as a systematic approach to concrete normative issues. A person facing a challenging situation can first of all have a moral intuition about what would be the right choice, based on personal moral convictions, more or less shared in the community or culture he belongs to. He can also engage in ethical analysis to clarify the issues at stake. When using the Navigation Wheel, ethics in a narrow sense consists in applying ethical principles and theories to a situation, while ethical analysis in a wider sense is understood as the application of the Navigation Wheel in a more comprehensive analysis.

The set of questions presented in the Navigation Wheel belongs to a family of such analytic sets, from the simple ones such as Blanchard and Peale's (1988): 'Is it legal, is it fair, can I defend it?', or Rion's (1990) 'Why is this bothering me? - Who else matters? - Is it my problem? - What is the ethical concern? - What do others think? - Am I being true to myself?' More complex approaches can be found in van Luijk's 8-question list (1994), the 8-step list of Laczniak and Murphy (1985), the 12-step list of Nash (1989) and the 10step list from the Markkula-center (2007).

The questions in the Navigation Wheel can be put to each alternative, in no particular order. It is also an open issue how they should be weighed and prioritised. Should ethical 
considerations trump economical ones, or vice versa? Is morality and doing the right thing more important than reputation? What should one do if the choice is between going economically bankrupt or compromising one's values and going bankrupt with regard to identity? The Navigation Wheel is not based on a particular theory of how to settle such issues.

Dilemmas arise when there is a tension between the answers you get from exploring alternatives in the light of the Navigation Wheel questions. They can be of a more general nature than traditional moral dilemmas, where the conflict is between two or more moral values. A business manager may face a dilemma where he has to prioritise between ethics and economy, reputation and morality, law and ethics, and so on.

In the following section, we discuss each of the six issues and questions in the Navigation Wheel.

\section{LAW: Is it legal?}

This question can involve national as well as international law. If the answer to this question is 'no', then any professional person has a strong reason to refrain from performing this action. The laws of a given society may not be perfectly matched with your personal morality and even be at odds with the more or less common morality of its citizens. Nevertheless, as a professional, you are bound by those laws and owe it to your employer to stay within the realm of the legal options. Civil disobedience is normally something that a person can perform as an individual, not as the employee of an organisation.

One interesting and important asymmetry with regard to the legal aspect is that the illegality of an action provides a reason to refrain, while the legality does not provide a corresponding reason to act in that particular way. There are plenty of perfectly legal actions open to a person that would be unwise to perform. The question 'How could you do such a thing?' can seldom be answered convincingly with the claim 'Because it was legal'. During ethical training and also in cases covered in the media, we have found that this asymmetry of the legal is often overlooked.

What about Ben's dilemma in the reference situation? According to national law, it is illegal to wilfully mislead or lie about a person's social competence in such a situation. You are not legally required to tell everything you consider relevant, but you can be prosecuted for lying. Some of the participants in our courses have said that they always give honest answers when they are reference persons but that they leave it to the questioner to identify the significant issues. If an employee is somewhat lacking in social skills, and the questioner only enquires about technical skills, then that is his responsibility. You are not legally required to bring attention to issues which the questioner has overlooked or seems to consider irrelevant.

\section{IDENTITY: Is it in accordance with our values?}

There can be two aspects to the question of identity. We have worked with people who are part of particular professions, with their own strong identities. Accountants world- 
wide identify with the values of integrity and objectivity, while practitioners in health institutions have a long tradition for caring and placing the patient's interest in the forefront. A parallel identity issue concerns the organisation's own identity. Since Collins and Porras (1996) documented the significance of core values for financial flourishing, there has been a growing interest in the maintenance of identity. Companies like Sony, Disney, Volvo and Nike have succeeded in staying loyal to their own core values and thus managed to establish an easily recognisable identity.

How does the identity question affect the circumstances of a business manager who is the reference person for an employee he would like to get rid of? We have presented the dilemma in one financial services organisation where one of the core values is 'team spirit. The participants found that the concept strongly discourages the alternative of being dishonest to a questioner from the same organisation. However, what about the circumstances where the employee has applied for a job with a competitor? Surely, a situation where he moves on will enhance team spirit? Taken in isolation, then, this value seems to favour being economical with the truth.

Values in the sense described here are not identical to moral values. 'Team spirit' can belong to the characteristics of an organisation and come into conflict with moral concerns. It can thus become an issue for consideration whether identity should trump morality, or vice versa. Something may have to give, and it can be a business manager's responsibility to decide which.

\section{MORALITY: Is it right?}

When considering the moral aspect of a situation, a person's convictions and beliefs about right and wrong set the framework. These can be more or less shared with other people who have grown up in a similar culture, under similar circumstances, and they affect the moral intuition or gut feeling the person has with regard with what should and should not be done in the concrete situation.

Is it morally acceptable to lie about a person's part in a conflict at work? Could such an action be considered a white lie? Most participants at our dilemma workshops conclude that the answer is no. From the point of view of morality, they argue, the lying option is clearly unacceptable. Honesty is a central tenet in society as we know it, making it disrespectful to tell lies. As indicated earlier, some claim that they will not tell a lie but refrain from bringing attention to dark issues not addressed by the questioner. In arguing that way, they rely on a distinction between what is active and what is passive, favoured by thinkers in the tradition of deontology. From this perspective, you are mainly accountable for the things you actively do and not so much for what you refrain from doing. During our courses, this view has been challenged by participants of a consequentialist persuasion. They believe that the distinction between active and passive is morally irrelevant. What matters morally, they claim, is the outcome of your decision, whether it is to do something or to remain passive. The outcome of Ben's reluctance to convey the relevant information about the employee can be that he receives a job offer on false premises. Ben could have stopped it and is morally accountable for his decision to keep quiet. 


\section{REPUTATION: Does it affect our goodwill?}

It is our experience that business people are deeply concerned with their reputation. They consider it to be a necessary asset in order to reach strategic and economical goals. It takes years to build good reputation, but it can be lost very quickly, is a commonly held view in business quarters.

Business leaders will protect their reputation even if that demands admitting to wrongdoing in cases where they have in fact acted responsibly and wisely. When the oil company Shell made plans to dispose of the oil storage facility Brent Spar, they consulted environment specialists and were advised that the safest option, both from an environmental and from an industrial health and security perspective, was to dispose of the construction in deep Atlantic waters. British authorities accepted the plan as the Best Practicable Environmental Option (Zyglidopolous 2002: 141-143). The activist group Greenpeace protested and started a campaign leading to widespread boycott of Shell service stations in European countries. In the end, Shell decided to abandon the plan in order to save reputation and avoid economical disruption. The company claimed that a better storage plan needed to be identified, although their own studies showed that deep-sea disposal was optimal from an environmental perspective. Later, Greenpeace had to acknowledge that the organisation had grossly overestimated the environmental damage of the proposed disposal of Brent Spar. By that time, however, the fight with Shell had been won, and the media was only mildly interested in Greenpeace's use of false numbers. The wisdom of giving in to pressure in such cases, in order to save reputation, has been questioned and analysed by Bowie and Dunfee, 2002.

In ethical training, our general approach is that each person and each working environment must decide how to rank the questions in the Navigation Wheel. We do, however, point to the disadvantages of giving top priority to reputation. For one, succumbing to media pressure can have a negative effect on internal morale. Insurance companies sometimes give in to such pressure and hand out money to customers who are not entitled to it whatsoever. They choose this option rather than to publicly challenge the distorted picture painted in the press. For the companies' employees, such capitulation can be a bitter blow to their motivation.

This is not to deny that reputation matters. Ben has good reasons to be concerned with the effect on his reputation in the aftermath of his efforts as a reference person. However, such considerations often take the attention away from the moral aspects of the options and instead focus on how they will be perceived by others. We once encountered a company whose identity and values statement said that 'It is our aim to be perceived as a service minded and open organisation'. The focus, then, was not on actually being service minded and open but on being perceived as an organisation with these qualities. If this is the dominant attitude, we can expect that the motivation for service-mindedness and openness is shallow and frail. It only emerges when there is a chance of scoring reputation points and not when public attention is absent. 


\section{ECONOMY: Is it in accordance with business objectives?}

Why is this question included among the ones a business person should ask himself when facing a dilemma? We have sometimes received the response that economy and ethics belong to different spheres and that profitability is not an issue to bring up in the ethical training of business people.

Our response is that many of the most significant dilemmas do involve the balancing of economical considerations with other aspects of the situation. As noted earlier, the choice under a given set of circumstances can be between going economically bankrupt or to go bust with regard to identity. There may be perfectly legal and profitable options available, which are at odds with the basic values a company has traditionally stood for. By choosing such an option, the company in a significant sense ceases to be the unit it has been. It may keep its name and address, but the break with one or more core values means that the identity is different now. A transformation has taken place.

With regard to Ben and his options in the reference dilemma, he can have short-term as well as long-term economical concerns. In the short term, results may improve if he remains tight-lipped about the employee's social troubles. The working environment will probably respond with relief and gain new energy with the removal of the cause of so much frustration. In the long term, however, this is a risky enterprise which may backfire on the unit as a whole and disrupt its ability to perform profitably.

\section{ETHICS: Can it be justified?}

This question invites a consideration of the alternatives in the light of ethical theories and principles.

A crucial tenet in ethical thinking from antiquity onwards is that when two sets of circumstances are equal in at least one morally relevant respect, they must be treated equally with regard to this respect. This is the generally accepted formal equality principle that Aristotle formulated in reference to Plato (Aristotle: 82-83). The principle of equality we use in our ethics training is stated as follows:

Equal cases should be treated equally. A difference in treatment requires that there is a morally relevant difference between the two cases.

We emphasise that this principle does not imply that everybody should be treated equally - which in our experience is necessary in order to prevent a common misunderstanding of this principle - they should only be treated equally if they have equal status in a morally relevant respect. The crucial question in concrete situations is what should count as a morally relevant difference.

We invite the participants to familiarise themselves with this way of reasoning through an exercise where they are required to identify morally relevant differences. What, for instance, is the morally relevant difference between gifts and bribes? You can become witness to circumstances where an object of value changes hands and be unable to determine whether what you have seen is that one person has received an innocent gift 
from another, or whether you have actually observed a case of bribery. What do you need to know in order to decide whether it is the one or the other? A list of relevant questions can look like this:

- What, if anything, does the giver hope to get in return from the receiver?

- More generally, what is the giver's motivation or intention?

- To what extent does the giver want to gain an improper advantage?

- What is the professional relationship between the two?

- What is the exact value of the object changing hands?

- At what stage in the professional relationship are they?

- Does the action take place before the receiver is to make a decision involving the giver or in the aftermath of such an event?

- To what extent does the local culture accept gifts between business relations?

These are all questions pointing to morally relevant aspects of the situation. The ensuing discussion often illustrates the need to look at all these aspects rather than single out a few of them.

A second ethical principle has to do with the extent to which a person's or a company's conduct will stand up to public scrutiny. The principle can be found in many versions in ethical guidelines in the professions and in company codes of conduct. One American lawyer we have worked with calls it 'the smell test': Does this particular action smell all right, or is there an unpleasant odour to it? Other phrases covering the same phenomenon are 'the public scrutiny test' and the 'light of day test'. An accountant prefers to call it 'the Aunt test'. His rule of thumb is to ask himself whether his aunt, a person of formidable integrity and wisdom, would have found his choice morally acceptable. The formulation we use for the principle of publicity is:

You should be willing to defend your decision publicly. To what extent can you be open about it to all the relevant people? To what extent can you tell your colleagues, friends, relatives and/or neighbours about it?

This principle is not a plea for you to spread your business secrets with the wind. It allows you to keep sensitive business information to yourself but challenges you to consider how your decisions would look to the public eye. Cross out the names of the companies and persons involved, and contemplate what kind of response you would get from people close to you if you chose this or that option in a dilemma.

An objection to the definition of the principle of publicity is that it is not really a principle formally on par with the principle of equality. Is it not simply an appeal to the agent to consider how he feels about a particular course of conduct? If so, is not the outcome more an expression of the person's morality rather than his ethical considerations, according to our initial distinction between those concepts?

Although we acknowledge the emotional and moral dimension of applying a 'public scrutiny' test, we still choose to label it as an ethical principle. It is not simply an advice to 
the effect that should look inwards and consult your feelings but also a cognitive element that can play a significant role in a person's reasoning about his choices.

In our training sessions, we have also found it useful to contrast the principle of publicity with a formally similar, but substantially different, principle of opportunism: How likely is it that you will have to defend your decision publicly and that other people will get to know about your decision? Participants thus get the opportunity to dwell on the important difference between an ethical and a reputational concern.

Obviously, there is more to ethics than just the two principles. In longer sessions, we also introduce the distinction between deontology and consequentialism. The latter reduces all morally relevant factors to consequences (Kagan 1998: 17-22), in contrast to the deontological tradition, which holds that some actions are morally forbidden, no matter how positive their outcomes are. We contrast the two traditions by defining deontology as being concerned with the quality of the action itself (the right), rather than with the outcome (the good), and the opposite consequentialist position of giving priority of the outcome (the good) over the way one acts (the right).

The reference dilemma serves well as an introduction to these two ethical traditions. From the perspective of deontology, lying is wrong and cannot be justified through an appeal to what the world will be like as a consequence of such an action. It may well be that the troublesome employee does more damage in his current position than he would do if he got the other job. All things considered, the outcome might be better if he could move on. In the eyes of a deontologist, however, this fact does not hold enough moral weight to justify lying. Honesty and respect for the questioner, and indeed also respect for himself as a moral being, requires Ben to tell the truth, no matter what the consequences will be. As noted earlier, duty ethics does not give him an obligation to bring up issues overlooked by the questioner, since it focuses solely on acts of commission and not on acts of omission.

\section{APPLICATION}

In the discussion and analysis of a particular dilemma, the focus can be on all six of the questions contained in the Navigation Wheel, or it can be on the tension between the answers we receive to two or more of the questions. The circumstances under consideration can exemplify the problem of having to prioritise between economy (here we have a potentially profitable business option) and identity (it is not really us to act that way), between ethics (according to the principle of equality we can do this) and reputation (it may nevertheless harm our public image), or between law (it is illegal) and morality (I believe it is the right thing to do).

During our dilemma training sessions, the participants are presented with a case for consideration and set out to 
1 Identify the relevant options available.

They are then asked to

2 Take each option through the relevant questions in the Navigation Wheel.

On the basis of their analysis, they should then

3 Make a decision.

If they are challenged on what they decide to do, they can provide a justification by referring to the process they have been through to prioritise in that way. The process involves two levels of justification. There is ethical justification in the narrow sense of providing reasons for your decision in the light of ethical principles, concepts and theories, and there is the more general ethical justification which can be explored through the use of the Navigation Wheel.

This distinction also addresses a question raised from time to time: Is ethics a part of the Navigation Wheel - so that the Navigation Wheel also can handle non-ethical issues - or is the Navigation Wheel in itself an ethical tool? In a narrow sense of ethics, ethics is a part of the Navigation Wheel in the sense that ethics as it is described as a part of the Navigation Wheel is the use of ethical principles and theories. However, we nevertheless maintain a wider sense of ethics, and that takes place when the Navigation Wheel is put to use.

We have applied the Navigation Wheel as a part of everything from a one-hour lecture on business ethics to more comprehensive processes in organisations, where the participants get training in using it at several points during a learning and development period. The participants are encouraged to use the Navigation Wheel actively in their everyday decision making outside the training period and to share it with colleagues. Feedback from former participants suggests a widespread use of the Navigation Wheel in organisations which have invested in dilemma training as a central element in the development of their employees.

\section{Conclusion}

We consider ethical training based on the principles and tools described in this article to be a fruitful way to prepare business leaders and others for the dilemmas they will face in their everyday working environment. So far, this conclusion has not been verified by systematic empirical evidence showing that the participants at our courses have significantly improved their ability to handle dilemmas. Instead, it is based on more sporadic feedback from participants and contact over time with business environments which have targeted ethics as an area for development and learning.

Mason (2010) has brought attention to the fact that unethical behaviour is still a problem in international business, in spite of the last decades' activities of ethical training in 
companies and in education. He argues that ethics education of this kind can serve to clothe unethical practices with ethical concepts and virtues. There is a danger that ethical training in business can be exploited in this manner, but we have seen plenty of sincere and systematic activity in business to address the issues and make people more competent in dealing with their challenges.

Participants at our dilemma training sessions return to a reality where they encounter dilemmas on a regular basis. Several of them report that the Navigation Wheel helps them to keep track of the relevant features of the situation and provides them with a tool to approach the circumstances in a systematic manner. Some also report that the systematic use of the Navigation Wheel can have an obviating and preventive effect: It can help people avoid getting into dilemmas. By using the Navigation Wheel to analyze a situation in advance, they can increase their ability to spot possible situations of dilemma that might occur with a given choice.

Our methodology has gradually evolved through interaction with the participants in our ethical training sessions. We thus believe that the content is well tuned to the challenges facing people whose professional lives are dominated by dilemmas. As noted by Bird and Waters (1989), business people need to develop confidence in articulating moral concerns. Further empirically oriented research should be developed to establish the extent to which this version of dilemma training actually is an effective way of learning practical ethics.

Ethical theory can play a part in handling and analysing dilemmas and other challenging situations. Dilemma training and other workshop methods can be used to explore the different dimensions of such situations and to prepare people for them. One limitation to these approaches, however, is that they do not directly develop the non-cognitive skills required to identify and respond to dilemmas. As noted by Maclagan, 'an issue may first come into light in the context of an emotionally stressful situation' (p. 31). The attributes needed to act well under such circumstances go beyond what can be acquired in dilemma training. Individuals and organisations committed to develop their responsiveness to ethical and moral challenges need to address both cognitive and non-cognitive attributes. The sensitivity to moral aspects of a situation can be brought up as a topic in workshops and seminars, but it can probably be most effectively addressed in the workplace and in concrete settings. The crucial role of business leaders and managers as role models in such situations is a topic for another article.

\section{Notes}

1 'Ethics' most often refers to a domain of inquiry, a discipline, in which matters of right and wrong, good and evil, virtue and vice are systematically examined. 'Morality', by contrast, is most often used to refer not to a discipline but to patterns of thought and action that are actually operative in everyday life. In this sense, morality is what the discipline of ethics is about. (Goodpaster 1992: 111)

2 'Ethics is concerned with the justification of actions and practices in specific situations. Ethics generally deals with the reasoning process and is a philosophical reflection on the moral life and the principles embedded in that life. Morality (...) generally refers to traditions or beliefs that have evolved 
over several years or even centuries in societies concerning right and wrong conduct. (Blanchard \& Rosenthal 1998: 4)

\section{Literature}

Aristotle (1984) Nicomachean Ethics. Trans. by Hippocrates G. Apostle. Grinnell, Iowa: The Peripatetic Press.

Bird, F.B. (1996) The Muted Conscience: Moral Silence and the Practice of Ethics in Business. Westport CT: Quorum Books.

Bird, F.B. \& Waters, J.A. (1989) The Moral Muteness of Managers. California Management Review, 32 (1), pp. 73-88.

Blanchard, K. \& Peale, N.V. (1988) The Power of Ethical Management. New York: William Morrow and Company.

Bowie, N.E. \& Dunfee, T.W. (2002) Confronting Morality in Markets. Journal of Business Ethics, 38 (4), pp. 381-393.

Brinkmann, J. (2005) Understanding Insurance Customer Dishonesty: Outline of a Situational Approach. Journal of Business Ethics, 61 (2), pp. 183-197.

Collins, J.C. \& Porras, J.I. (1996) Building Your Company's Vision. Harvard Business Review, 74 (5), pp. 65-77.

Forsyth, D.R. (1980) A taxonomy of ethical ideologies. Journal of Personality and Social Psychology, 39, pp. 175-184.

Hill, T.E. (1985) Servility and Self-Respect. In Today's Moral Problems, 3. edition, ed. R.A. Wasserstrom, pp. 70-84. New York: Macmillan.

Jackson, J. (1996) An Introduction to Business Ethics. Oxford: Blackwell.

Kagan, S. (1998) Normative Ethics. Boulder: Westview.

Kidder, R.M. (1995) How Good People Make Tough Choices. New York: Fireside.

Van Luijk, H.J. (2004) Integrity in the Private, Public and Corporate Domain. In Corporate Integrity and Accountability, ed. G. Brenkert, pp. 38-54. Thousand Oaks, CA: Sage.

Van Luijk, H.J. (2000) In Search of Instruments. Business and Ethics Half Way. Journal of Business Ethics, 27 (1-2), pp. 3-8.

Laczniak, G.R. \& Murphy, P.E (1985) Marketing ethics. Lexington: Lexington Books.

Maitland, I. (2002) The Human Face of Self-Interest. Journal of Business Ethics, 38 (1-2), pp. 3-17.

Markkula Center for Applied Ethics, University of Santa Barbara. A Framework for Thinking Ethically. Retrieved 15. January 2012 from

http://www.scu.edu/ethics/practicing/decision/framework.html

Marinoff, L. (2002) Philosophical Practice. San Diego, CA: Academic Press.

Mason, J.D. (2010) The Ethical Dilemma of Teaching Ethics: Clothing Unethical Practices with Ethical Virtues. Journal of Leadership, Accountability \& Ethics, 8 (1), pp. 34-44.

Mclagan, P. (2003) Varieties of Moral Issue and Dilemma: A Framework for the Analysis of Case Material in Business Ethics Education. Journal of Business Ethics, 48 (1), pp. 21-32.

Nash, L.L. (1989) Ethics without the Sermon. In Ethics in Practice, ed. K.R. Andrews, pp. 243-257. Boston: HBS Press.

Rion, M. (1990) The Responsible Manager. New York: Harper Collins.

Toffler, B.L. (1986) Tough Choices: Managers Talk Ethics. New York: John Wiley and Sons.

Zyglidopoulos, S.C. (2002) The Social and Environmental Responsibilities of Multinationals: Evidence from the Brent Spar Case. Journal of Business Ethics, 36 (1/2), pp. 141-151. 